Journal of Community Based Environmental Engineering and Management, 2019, Vol. 3, No. 1: 9-14

\title{
IDENTIFIKASI NILAI LAJU DEOKSIGENASI DI DAERAH PADAT PENDUDUK (STUDI KASUS SUNGAI CICADAS, BANDUNG)
}

\author{
Yonik Meilawati Yustiani", Sri Wahyuni, Arry Akbar Abdul Kadir \\ Program Studi Teknik Lingkungan, Universitas Pasundan
}

\begin{abstract}
Abstrak
Buangan limbah cair yang berasal dari kegiatan domestik mengandung BOD yang relatif tinggi. Secara alamiah, polutan organik yang masuk ke badan air penerima dapat didegradasi melalui proses self purification. Proses degradasi ini dapat direprestasikan dengan penurunan oksigen atau deoksigenasi, sedangkan laju deoksigenasi menandakan kecepatan degradasi tersebut berlangsung. Penelitian ini bertujuan untuk mendapatkan nilai laju deoksigenasi di Sungai Cicadas, Bandung, yang memiliki pencemaran berat akibat buangan cair dari daerah padat penduduk. Metode yang digunakan adalah pengamatan laboratorium selama 10 hari pada sampel yang diambil di 3 titik. Pengolahan data yang dilakukan menggunakan Metode Slope. Selain itu, laju deoksigenasi juga dihitung menggunakan rumus empiris yang dikeluarkan oleh Hydroscience. Hasil penelitian ini menunjukkan bahwa laju deoksigenasi berkisar antara 0,01 hingga 0,17 per hari. Jika dibandingkan dengan hasil perhitungan menggunakan rumus empiris, nilai ini sangat kecil. BOD ultimate yang diperoleh memiliki rentang antara 42,76 hingga $682 \mathrm{mg} / \mathrm{L}$. Nilai laju deoksigenasi yang rendah ini memperlihatkan bahwa walaupun limbah dari kegiatan domestik mudah didegradasi, namun proses degradasi dapat berlangsung lambat akibat faktor-faktor penghambat yang kemungkinan terjadi pada sungai tersebut.
\end{abstract}

Kata kunci: Laju deoksigenasi, limbah domestik, Sungai Cicadas

\section{Pendahuluan}

Sungai Cicadas adalah salah satu sungai yang berada di Kota Bandung. Lokasi hulu Sungai Cicadas berada di TMP Cikutra dengan hilir berada di Sungai Citarum. Panjang Sungai Cicadas berkisar $18 \mathrm{Km}$ dengan debit 15 $\mathrm{m}^{3} /$ detik. Permasalahan yang terjadi di Sungai Cicadas kerap terjadi disebabkan adanya sampah, limbah domestik dan limbah industri. Permasalahan ini menyebabkan kualitas air di Sungai Cicadas Sungai berkurang.

\footnotetext{
${ }^{*}$ Penulis Korespondensi:
}

E-mail: yonik@unpas.ac.id

Diterima pertama kali: 10 Desember 2018

Direvisi : 15 Desember 2018

Disetujui untuk publikasi: 30 Desember 2018
Laju deoksigenasi adalah kecepatan penurunan nilai oksigen yang terlarut di dalam air karena telah digunakan oleh bakteri aerob untuk menguraikan zat-zat organik yang dapat menurunkan kualitas air sungai (Chapra, 2015).

Nilai konstanta $\mathrm{K}_{1}$ (koefisien deoksigenasi) air sungai dapat menunjukkan kecepatan penurunan konsentrasi oksigen karena digunakan oleh mikroorganisme untuk proses penguraian materi organik yang terdapat dalam air sungai. Semakin besar nilai $\mathrm{K}_{1}$ menandai semakin besarnya kemampuan sungai untuk melakukan dekomposisi dan purifikasi secara alamiah.

Nilai koefisien laju deoksigenasi yang akan diperoleh berupa rentang untuk Sungai Cicadas. Nilai ini dapat digunakan untuk pemodelan kualitas air baik pada proses perkiraan kualitas 
sungai pada saat ini maupun prediksi di masa yang akan datang. Hasil perhitungan model menggunakan nilai koefisien laju deoksigenasi yang sesuai dengan kondisi Sungai Cicadas akan memberikan gambaran mengenai karakteristik lingkungan sungai tersebut. Oleh karena itu, penelitian mengenai laju deoksigensi pada Sungai Cicadas perlu dilakukan.

\section{Metodologi Penelitian}

\section{Tahapan Penelitian}

Tahapan penelitian dapat dilihat pada Gambar 1.

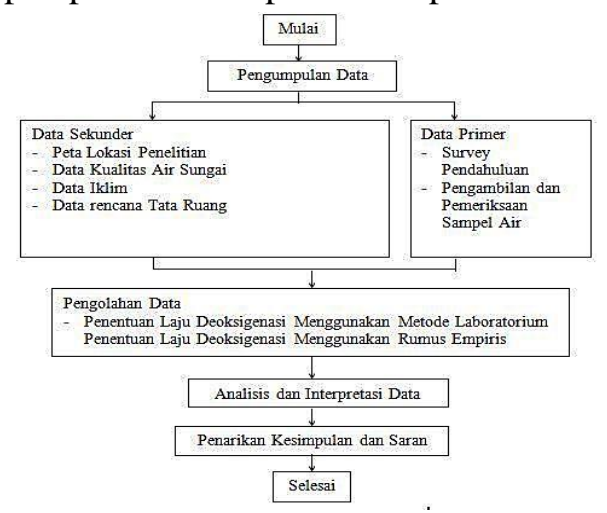

\section{Lokasi Pengambilan Sampel}

Pengambilan sampel dalam penelitian ini dilakukan pada 3 lokasi di Sungai Cicadas, yaitu bagian hulu, tengah dan hilir. Pada setiap lokasi diambil 1 titik tengah sungai. Lokasi pertama yang dijadikan sebagai segmen hulu lokasinya yaitu terletak di jalan PHH Mustofa tepatnya pada kordinat LS 6 53 '53.62" \& BT 107³8'6.51",dan lokasi kedua yaitu bagian tengah berada di jalan Tol Purbaleunyi tepatnya di koordinat LS 6 ${ }^{\circ} 58^{\prime} 10.94 "$ \& BT 107³9'35.85", dan lokasi ketiga yaitu bagian hilir berada di jalan Cibojong Haur Hapit tepatnya di kordinat LS $7^{\circ} 0^{\prime} 22.63 "$ \& BT 107³8'34.49". Penentuan titik sampel diharapkan dapat mewakili kondisi kualitas air sungai, dan tingkat pencemaran yang diakibatkan oleh berbagai kegiatan yang terdapat di wilayah daerah aliran sungai,atau domestik.

Berikut peta lokasi pengambilan sampel pada Gambar 2.

Gambar 1. Tahapan Penelitian

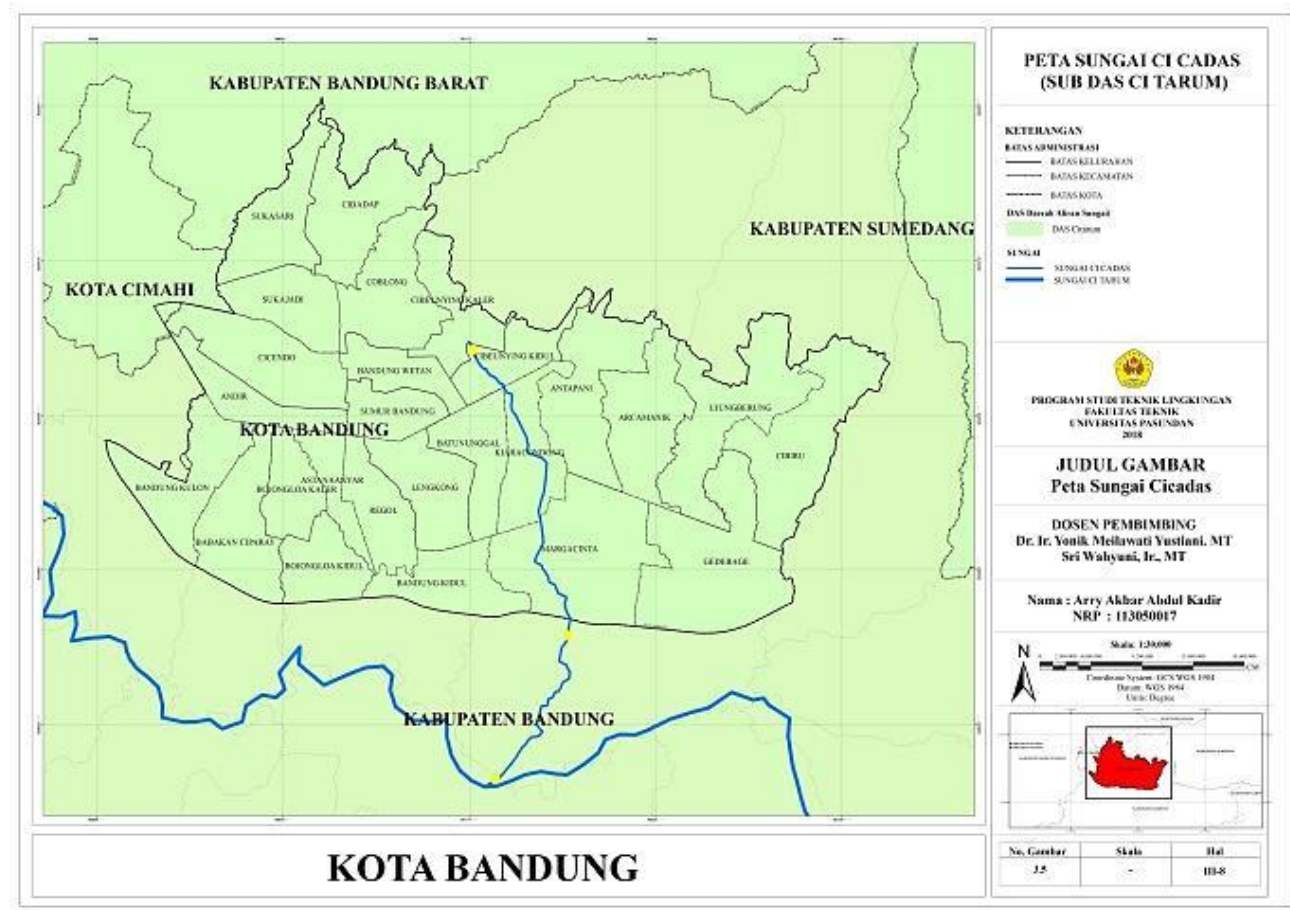

Gambar 2. Sungai Cicadas dan Sungai Citarum 


\section{Pengukuran Setempat}

Pemeriksaan setempat yang dilakukan di lokasi pengambilan sampel yaitu debit, suhu, $\mathrm{pH}$ dan DO (Dissolved Oxygen). Pengukuran debit meliputi beberapa pengukuran, diantaranya adalah pengukuran kedalaman, lebar sungai dan kecepatan aliran sungai.

Pada pengukuran kedalaman dilakukan dengan menggunakan alat yang terbuat dari kayu yang memiliki ukuran, penggunaan alat ini cukup mudah hanya dengan memasukkannya kedalam sungai secara tegak.Pada pengukuran lebar sungai dengan menggunakan meteran yang dibentangkan dari satu sisi ke sisi lainnya. Pada pengukuran kecepatan alat yang digunakan adalah bola tenis meja yang diikat dengan benang dan stopwatch, sehingga didapat besarnya kecepatan air dalam satuan meter per detik.

Pengukuran suhu dilakukan dengan menggunakan termometer. Penggunaan alat inidengan memasukkan bagian yang terdapat air raksanya, lihat pergerakan air raksa yang terdapat di dalam termometer tersebut sampai berhenti, kemudian catat hasil yang terukur.

Pengukuran $\mathrm{pH}$ dan DO dilakukan dengan menggunakan alat digital seperti $\mathrm{pH}$ meter dan DO meter. Penggunaan alat ini juga mudah dengan cara mencelupkan bagian detektornya, yang kemudian hasilnya akan tertera pada masing-masing layar alat tersebut.

\section{Pengambilan Sampel}

Pengambilan sampel air ini dilakukan di 3 lokasi, masing-masing lokasi terdapat 1 titik sampel dengan tiga kali pengambilan sampel di titik yang sama, pengambilan tiap titik dilakukan untuk memperoleh data yang mewakili kondisi waktu, keadaan tertentu agar memperolehnilai data rata-rata yang lebih baik.

\section{Analisis Laboratorium untuk Menentukan} LajuDeoksigenasi dan BOD Ultimate

Setelah contoh air diambil dengan prosedur yang sesuai, dilakukan pemeriksaan kualitas air di Laboratorium. Pemeriksaan yang dilakukan untuk menentukan laju deoksigenasi adalah pemeriksaan parameter DO. Proses inkubasi menggunakan botol BOD, dilakukan selama 10 hari dalam inkubator $20^{\circ} \mathrm{C}$. Konsentrasi DO diukur tiap hari berdasarkan metode modifikasi Winkler (APHA, 2012) dengan menggunakan rumus perhitungan sebagai berikut :

$$
D O(m g / L)=\frac{\mathrm{V} \times \mathrm{N} \times 8000 \times \mathrm{F}}{\mathrm{V} \text { sampel }}
$$

Dimana :

$\mathrm{V}=$ Volume titrant $\mathrm{Na}_{2} \mathrm{~S}_{2} \mathrm{O}_{3}(\mathrm{ml})$

$\mathrm{N}=$ Normalitas $\mathrm{Na}_{2} \mathrm{~S}_{2} \mathrm{O}_{3}$

$\mathrm{F}=$ Faktor Botol

Metode slope Thomas, digunakanuntuk mengestimasi parameter BOD dengan rumus sebagai berikut :

$$
y^{\prime}=\frac{(\Delta y i-1)\left(\frac{\Delta t i+1}{\Delta t i-1}\right)+(\Delta y i+1)\left(\frac{\Delta t i-1}{\Delta t i+1}\right)}{(\Delta t i-1)+(\Delta t i+1)}
$$

Dimana:

$\Delta y i-1=$ selang DO loss sebelum

$\Delta y i+1=$ selang DO loss sesudah

$\Delta t i+1=$ selang waktu sebelum

$\Delta t i-1=$ selang waktu sesudah

Penentuan Laju Deoksigenasi Menggunakan PersamaanEmpiris

Dalam penentuan laju deoksigenasi dengan menggunakan rumus empiris ini dengan mempertimbangkan faktor lingkungan seperti kedalaman sungai. Kedalaman sungai berpengaruh terhadap kehidupan mikroorganisme yang ada di dalamnya,semakin besar kedalaman sungai akan semakin sedikit kandungan oksigennya dan sedikit juga jumlah mikroorganisme yang dapat hidup di perairan tersebut.Koefisien deoksigenasi yang digunakan 
untuk perhitungan model pencemaran organik dalam air ditentukan menggunakan formula menurut Hydroscience (Chapra, 2015) untuk aliran normal adalah sebagai berikut :

$$
\begin{array}{r}
\checkmark \quad \text { Jika } 0 \leq \mathrm{H} \leq 8 \mathrm{ft} \rightarrow 0 \leq \mathrm{H} \leq 2,4 \mathrm{~m}, \\
\text { maka } \\
K_{1}=0,3 \times\left(\frac{H}{8}\right)^{-0,434} \\
\checkmark \quad \text { Jika } \mathrm{H}>8 \mathrm{ft} \rightarrow \mathrm{H} \geq 2,4 \mathrm{~m} \\
K_{1}=0,3
\end{array}
$$

Dimana :

$$
\begin{array}{ll}
\mathrm{K}_{1} & =\text { koefisien deoksigenasi }\left(\text { hari }^{-1}\right) \\
\mathrm{H} & =\operatorname{kedalaman}(\mathrm{ft})
\end{array}
$$

\section{Hasil dan Pembahasan \\ Hasil Pengukuran Debit}

Tabel 1 memperlihatkan hasil dari perhitungan debit sungai Cicadas. Debit air diperoleh dengan

\begin{tabular}{|c|c|c|c|c|c|c|c|}
\hline \begin{tabular}{|c} 
No \\
Sampel
\end{tabular} & $\begin{array}{l}\text { d rata-rata } \\
\text { (meter) }\end{array}$ & \begin{tabular}{|c|} 
rata-rata \\
(detik)
\end{tabular} & \begin{tabular}{|c} 
D \\
(meter)
\end{tabular} & $\begin{array}{c}\mathrm{L} \\
\text { (meter) }\end{array}$ & $\begin{array}{c}\mathrm{A} \\
\left(\mathrm{m}^{2}\right)\end{array}$ & $\begin{array}{c}\mathrm{V} \\
(\mathrm{m} / \mathrm{det})\end{array}$ & $\begin{array}{c}Q \\
\left(\mathrm{~m}^{3} / \mathrm{det}\right)\end{array}$ \\
\hline Hulu 1 & 0,17 & 6,96 & 2 & 1,3 & 0,221 & 0,287 & 0,063 \\
\hline ulu 2 & 0,17 & 6,96 & 2 & 1,3 & 0,221 & 0,287 & 0,063 \\
\hline Hulu 3 & 0,17 & 6,96 & 2 & 1,3 & 0,221 & 0,287 & 0,063 \\
\hline Tengah 1 & 0,093 & 33,60 & & 9,3 & 0,865 & 0,030 & 0,026 \\
\hline Tengah 2 & 0,093 & 33,60 & & 9,3 & 0,865 & 0,030 & 0,026 \\
\hline Tengah 3 & 0,093 & 33,60 & & 9,3 & 0,865 & 0,030 & 0,026 \\
\hline Hilir 1 & 0,0655 & 4,75 & 2 & 6,55 & 0,4290 & 0,421 & 0,181 \\
\hline Hilir 2 & 0,0655 & 4,75 & 2 & 6,55 & 0,4290 & 0,421 & 0,181 \\
\hline Hilir 3 & 0,0655 & 4,75 & 2 & 6,55 & 0,4290 & 0,421 & 0,181 \\
\hline
\end{tabular}
menggunakan rumus:

$\operatorname{Debit}(\mathrm{Q})=\mathrm{V} \times \mathrm{A}$

Dimana :

$\mathrm{V}=$ Kecepatan

$\mathrm{A}=$ Luas Penampang

Tabel 1. Hasil Perhitungan Debit Sungai

Keterangan :

$\mathrm{d}$ : Kedalaman sungai

$\mathrm{t}$ : Waktu rata-rata kecepatan sungai

D : Jarak antara titik 1 dan 2

L : Lebar Sungai

A : Luas Penampang
$\mathrm{V}:$ Kecepatan air sungai

Q : Debit sungai

Debit yang diperoleh dari perhitungan relatif kecil karena dipengaruhi kecepatan aliran sungai

\begin{tabular}{|c|c|c|c|}
\hline \multirow[t]{2}{*}{ Titik Lokasi } & \multicolumn{3}{|c|}{ Parameter } \\
\hline & DO & $\mathrm{pH}$ & Suhu \\
\hline Hulu I & $4,1 \mathrm{mg} / 1$ & 7,57 & $23,3^{\circ} \mathrm{C}$ \\
\hline Hulu II & $2,3 \mathrm{mg} / 1$ & 7,11 & $22,7^{\circ} \mathrm{C}$ \\
\hline Hulu III & $4,2 \mathrm{mg} / 1$ & 7,13 & $22,9^{\circ} \mathrm{C}$ \\
\hline \multirow[t]{2}{*}{ Titik Lokasi } & \multicolumn{3}{|c|}{ Parameter } \\
\hline & DO & $\mathrm{pH}$ & Suhu \\
\hline Tengah 1 & $3,2 \mathrm{mg} /$ & 7,30 & $28,6^{\circ} \mathrm{C}$ \\
\hline Tengah 2 & $3,0 \mathrm{mg} / 1$ & 7,26 & $28,9^{\circ} \mathrm{C}$ \\
\hline Tengah 3 & $2,6 \mathrm{mg} / 1$ & 7,01 & $29,2^{\circ} \mathrm{C}$ \\
\hline \multirow[t]{2}{*}{ Titik Lokasi } & \multicolumn{3}{|c|}{ Parameter } \\
\hline & DO & $\mathrm{pH}$ & DO \\
\hline Hilir I & $4,1 \mathrm{mg} / 1$ & 6,60 & $29,6^{\circ} \mathrm{C}$ \\
\hline Hilif II & $4,8 \mathrm{mg} / \mathrm{I}$ & 6,93 & $29,3^{\circ} \mathrm{C}$ \\
\hline Hilir III & $4,0 \mathrm{mg} / 1$ & 7,17 & $29,1^{\circ} \mathrm{C}$ \\
\hline
\end{tabular}
yang kecil dan bentang sungai yang lebar.

\section{Pengukuran Langsung DO, pH, Suhu}

Tabel 2 adalah hasil pengukuran langsung di lapangan.

Tabel 2. Hasil Pengukuran Langsung DO, pH, Suhu

\section{Hasil Analisis Laboratorium untuk Laju} Deoksigenasi dan BOD Ultimate

DO Loss adalah nilai penurunan DO setiap harinya dengan menggunakan metode Winkler Gambar 3 memperlihatkan hasil DO Loss di segmen hulu :

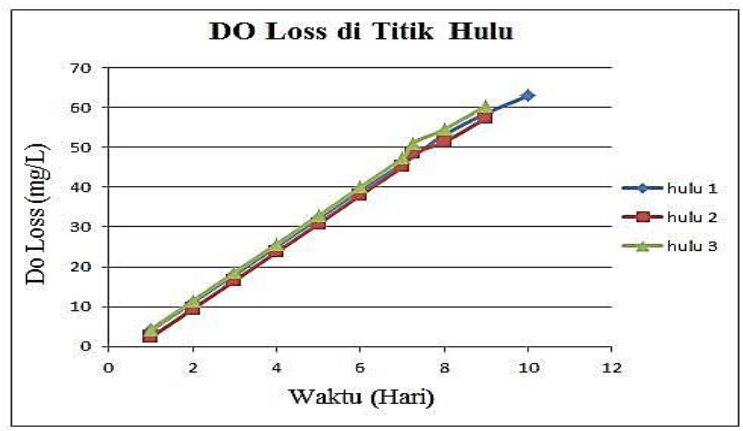

Gambar 3. DO Loss Segmen Hulu 
Secara keseluruhan apabila digabungkan dan diambil nilai rentang laju deoksigenasi (K1) untuk titik hulu pada Sungai Cicadas berkisar antara 0,01 hingga 0,07 per hari.

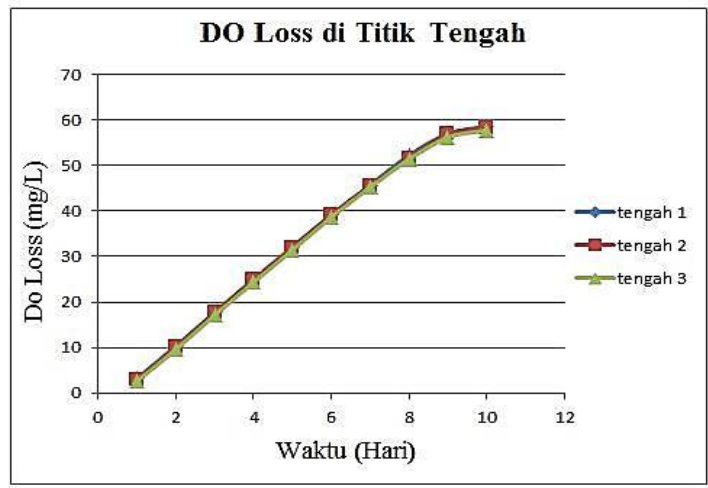

Gambar 4. DO Loss Segmen Tengah

Untuk nilai laju deoksigenasi (K1) pada titik tengah berkisar 0,03 per hari.

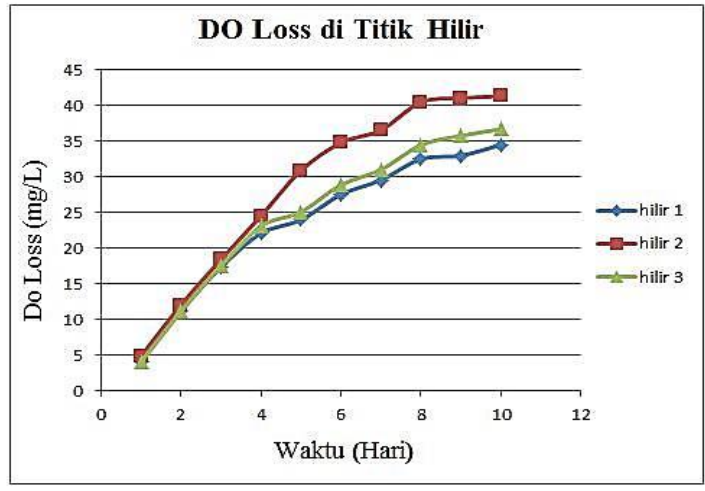

Gambar 5. DO Loss Segmen Hilir

Untuk nilai laju deoksigenasi (K1) pada titik hilir berkisar 0,13 hingga 0,17 per hari. Nilai Deoksigenasi di hulu, tengah dan di hilir berbeda menunjukan aktivitas mikroorganisme yang ada dalam pemakaian oksigen dalam mendegradasikan zat organik berbeda-beda.

Nilai BOD Ultimate diperoleh menggunakan analisis laboratorium pada setiap sampel. BOD Ultimate adalah oksigen terlarut yang dibutuhkan oleh mikroorganisme untuk menguraikan senyawa organik secara sempurna. Tabel 3 adalah hasil BOD ultimate di setiap titik sampel.
Tabel 3 Hasil Nilai Laju Deoksigenasi dan BOD Ultimate

\begin{tabular}{|c|c|c|}
\hline Titik Sampling & $\begin{array}{c}\text { Laju Deoksigenasi Kl } \\
\text { (per hari) }\end{array}$ & $\begin{array}{c}\text { BOD Ultimate La } \\
\text { (Mg/L) }\end{array}$ \\
\hline Hulu 1 & 0,01 & 682 \\
\hline Hulu 2 & 0,06 & 176,66 \\
\hline Hulu 3 & 0,07 & 165,85 \\
\hline Tengah 1 & 0,03 & 238 \\
\hline Tengah 2 & 0,03 & 237,66 \\
\hline Tengah 3 & 0,03 & 236 \\
\hline Hilir 1 & 0,17 & 42,76 \\
\hline Hilir 2 & 0,13 & 59,76 \\
\hline Hilir 3 & 0,15 & 48,4 \\
\hline Rata - rata hulu & 0,046 & 341,50 \\
\hline Rata - rata & 0,03 & 237,22 \\
\hline tengah & 0,15 & 50,30 \\
\hline Rata - rata hilir & &
\end{tabular}

Nilai Deoksigenasi di hulu, tengah dan di hilir berbeda menunjukan aktivitas mikroorganisme yang ada dalam pemakaian oksigen dalam mendegradasikan zat organik berbeda-beda.

Sedangkan untuk nilai BOD Ultimate pada Sungai Cicadas secara keseluruhan antara 42,76 mg/L hingga 682 mg/L.

\section{Hasil Perhitungan Rumus Empiris}

Setelah dilakukan pengukuran kedalaman Sungai Cicadas di titik hulu, tengah dan hilir diperoleh hasil yang tidak melebihi 2 meter, sehingga rumus yang digunakan sebagai berikut:

$$
K_{1}=0,3 \times\left(\frac{H}{8}\right)^{-0,434}
$$

Dimana :

$$
\begin{array}{ll}
\mathrm{K}_{1} & =\text { Koefisien deoksigenasi }\left(\text { hari- }^{1}\right) \\
\mathrm{H} & =\text { Kedalaman sungai }(\mathrm{ft})
\end{array}
$$

Tabel 4. Perhitungan Empiris

\begin{tabular}{|c|c|c|c|}
\hline Titik Sampling & \multicolumn{2}{|c|}{ Kedalaman (H) } & Laju Deoksigenasi(per hari) \\
\cline { 2 - 3 } & meter & feet & \\
\hline Hulu & 0,17 & 0,55 & 0,958 \\
\hline Tengah & 0,53 & 1,73 & 0,583 \\
\hline Hilir & 0,13 & 0,42 & 1,077 \\
\hline
\end{tabular}

Rentang nilai laju deoksigenasi pada Sungai Cicadas pada penelitian ini berkisar antara 0,01 
hingga 0,17 per hari dengan analisis laboratorium, sedangkan untuk rumus empiris berkisar antara 0,583 hingga 1,077 per hari. hal ini terjadi karena rumus empiris ini merupakan rumus yang diterapkan pada sungai yang memiliki aktivitas mikroorganisme yang relatif tinggi sehingga nilai laju deoksigenasi akan besar.

\section{Analisis Laju Deoksigenasi Sungai Cicadas}

Hasil laju deoksigenasi dengan analisis lab adalah sebesar 0,01 hingga 0,17 per hari. Sedang perhitungan dengan rumus empiris, menghasilkan laju deoksigenasi sebesar 0,583 hingga 1,077 per hari. Besarnya nilai laju deoksigenasi hasil dari menggunakan rumus empiris dipengaruhi oleh faktor lingkungan yang terjadi di Sungai Cicadas. Dimana faktor lingkungan cenderung membuat nilai laju deoksigenasi lebih besar di bandingkan dengan menggunakan analisis laboratorium.

Nilai laju deoksigenasi Sungai Cicadas ini mirip dengan sungai lainnya yang ada di Jawa Barat, antara lain Sungai Cimanuk 0,06-0,12 /hari (Yustiani, Sri Wahyuni, \& Alfian, 2018), Sungai Citarum 0,10-0,17 /hari (Ayudina, 2017).

\section{Kesimpulan}

Hasil pengulangan laju deoksigenasi dengan analisis lab adalah sebesar 0,01 hingga 0,17 per hari dan nilai BOD Ultimatenya berkisar 42,76 mg/L hingga $682 \mathrm{mg} / \mathrm{L}$. Sedang perhitungan dengan rumus empiris, menghasilkan laju deoksigenasi sebesar 0,583 hingga 1,077 per hari.

Dari hasil di atas terlihat bahwa nilai rentang laju deoksigenasi $\left(\mathrm{K}_{1}\right)$ dengan menggunakan analisis laboratorium lebih kecil dibandingkan nilai rentang laju deoksigenasi $\left(\mathrm{K}_{1}\right)$ dengan menggunakan rumus empiris. Kondisi nilai BOD Ultimate memperlihatkan bahwa banyaknya zat organik yang terkandung di dalam air Sungai Cicadas, disebabkan aliran Sungai Cicadas yang melewati daerah pemukiman yang sebagian besar limbahnya mengandung zat organik yang akan meningkatkan pemakaian oksigen oleh mikroorganisme untuk mendegradasi zat organik tersebut. Semakin besar nilai BOD, maka semakin kecil ketersediaan oksigen terlarut dalam air.

\section{Daftar Pustaka}

Ayudina, A. (2017). Penentuan Nilai Koefisien Laju Deoksigenasi di Sungai Citarum Segmen Tengah. Bandung: Tugas Akhir Prodi TL UNPAS.

Chapra, S. (2015). Surface Water Quality Modeling. New-Delhi: Medtech.

Yustiani, Y. M., Sri Wahyuni, S., \& Alfian, M. R. (2018). Investigation on the deoxygenation rate of water of Cimanuk river, Indramayu, Indonesia. Rasayan J.Chem. , Vol 11, No. 2: 475-481. 